\title{
The oral health related quality of life in different groups of senior citizens as measured by the OHIP-14 questionnaire
}

\author{
William Papaioannou ${ }^{1 *}$, Constantine J. Oulis ${ }^{2}$ and John Yfantopoulos ${ }^{3}$
}

*Correspondence: vpapaio@dent.uoa.gr

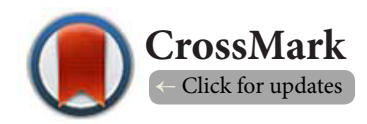

'Department of Preventive and Community Dentistry, School of Dentistry, University of Athens, Greece.
2Department of Paediatric Dentistry, School of Dentistry, University of Athens, Greece.
${ }^{3}$ School of Law, Economic and Political Sciences, University of Athens, Greece.

\begin{abstract}
Objective: The present study aimed to investigate the impact of the oral health status on the quality of life of groups of elderly adults in urban and rural regions of Greece with different educational backgrounds.

Background: Health-Related Quality of Life (HRQoL) is significantly affected by an individual's oral health status.

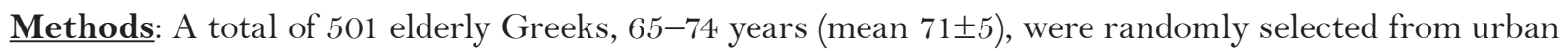
and rural areas. In a face to face survey, they completed a self-administrated questionnaire, containing the OHIP-14 instrument validated for Greeks. Difference in the OHIP among urban vs rural and metropolitan vs non metropolitan populations as well as among five educational classes are assessed. Furthermore comparisons are drawn between subjective general and oral health.
\end{abstract}

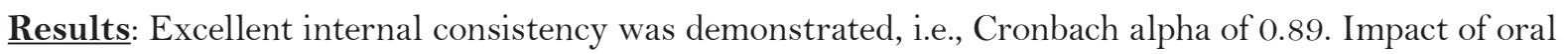
health on quality of life was found with a weighted OHIP-14 score of 2.1 (s.d. 2.7). Functional limitation, physical pain and psychological discomfort were the highest scoring, even surpassing a mean of 3 . The overall level of Oral Health Related Quality of Life (OHRQoL) was better in urban (OHIP-ADD 15.6+/11.0) than in rural (OHIP-ADD 16.3+/-10.0) areas and in metropolitan (OHIP-ADD 14.7+/-11.0) than in non-metropolitan (OHIP-ADD 16.4+/-10.0) areas. Significant educational differences in the OHRQoL were identified between those with lower educational class (OHIP-ADD 16.0+/-10.3) in comparison with those with higher (OHIP-ADD 13.0+/-11.3) educational level. Finally drawing comparisons between general and oral health it was found that $65 \%$ of the rural population reports good general health and around the half $35 \%$ reported good oral health. This difference is attributed to the lack of oral health planning in the rural areas of Greece.

Conclusions: Dental and oral health conditions have a measurable impact on the quality of life of senior citizens. The ability of an individual to function can be affected, which in turn can have more far-reaching economic impacts on society as a whole.

Keywords: Oral health related quality of life (OHRQoL), OHIP-14, senior citizens, perceived health

\section{Background}

The Quality of Life (QoL) a person enjoys may have an affect on the individual's health and on his or her daily activity. However, this relationship between quality of life and health is a twoway relationship. The health of an individual can in turn have a significant impact on the daily activities of said individual. This impact may further reduce the individual's functionality and psychological well-being. Empirical analysis has revealed that Health-Related Quality of Life (HRQoL) is closely related to demographic (age, gender) social, economic and cultural aspects [1].

The reason that Health-Related Quality of Life is an emerging subject of importance during recent years is precisely because it has been accepted that the effects of a disease or condition 
Papaioannou et al. Oral Biology and Dentistry 2015,

are more disperse than just the strict effect on a specific organ or system of the individual. This means that the results of a disease or condition cannot be fully determined by using solely clinical measures, since these do not consider the subjective experiences, personal values, attitudes and beliefs that individuals have concerning their personal assessment of health [2]. Thus, quality of life measures are of importance to look further and beyond than just the presence of health or disease, which are covered by the clinical sciences and their specific measures, and more into the way that the individual perceives his state of health and, in turn, how this impacts on his daily performance. Moreover, data obtained from these types of measures are of special importance when considering health care and how it is provided to different groups and if it is according to the specific needs they may have. HealthRelated Quality of Life is, indeed, now widely considered by the international organizations such as the W.H.O., the OECD and Eurostat as a substantive and valid measure for the assessment of healthcare outcomes.

One of the major factors that can significantly affect the overall HRQoL is the oral health of the individual $[3,4]$. Its effects can be far reaching, leading to a diminishment of daily function as well as the well being of an individual, which can even lead to his/her physical or psychological incapacitation. The costs and complications from such a condition have been determined to be great not only for the specific individual but to society as a whole [5]. This applies to all societies in general both rich and poor, developed and less developed. It is obvious that the consideration of the impact of quality of life, especially when considering economic resources and finance allocation in health planning and specifically for oral health planning, is in the end for the good of the individual and society. The importance of HRQoL and its oral health facet has led to the development of a large spectrum of measures in dentistry over the last two decades, to capture the impact of oral disorders both on patients' physical and psychological as well as social well-being and their ability to perform daily activities $[6,7]$. From these, the Oral Health-Related Quality of Life $(\mathrm{OHRQ} \mathrm{L}$ ) measurements have been developed.

The Oral Health Impact Profile in its short form (OHIP-14), developed by Slade and Spencer [8] for the measurement of disability and discomfort due to oral conditions, is one of the most widely known OHRQoL instruments. It comprises 14 items which were derived from the original 49-items version [9]. From these items seven sub-scales are subsequently made based on the conceptual oral health framework suggested by Locker [10] and derived from the World Health Organization [11]. In general, the short form of the OHIP is less time-consuming and more practical but with comparable reliability and validity with the long version $[\mathbf{9 , 1 2}$.

The oral health status of individuals can be affected by many personal, social, economic, cultural and local factors. Different regions within a country or between countries and geographical locations can account for differences in the oral health status. Indeed, in a recent epidemiological study in Greece, significant differences were found between different regions and between urban and rural (agricultural) areas for the oral status of the inhabitants of these regions [13]. Knowing that these differences are present, it is of interest to also compare the different regions for the impact of their oral status on the OHRQoL of the individuals.

The aim of the present study was to investigate and report on the impact of oral health status on the quality of life in populations of senior citizens. A cross section of Greek adults aged 65 to 74 years old belonging to different population groups in diverse regions in terms of income and economic development of the country was examined in order to determine this impact.

\section{Materials and methods}

This is a cross-sectional study based on a random sample consisting of a total of 501 elderly Greek adults between the ages of $65-74$ years (mean $71 \pm 5$ ). The study was organized by the Greek Dental Association in collaboration with the Dental School of the University of Athens. Sampling methodology was designed and implemented by a group of experts at the University of Athens in close collaboration with experts from the Hellenic National Statistical Services. A three stage sampling process was executed based on the 2011 census survey. At the first stage the regions of Greece were stratified by allocating the municipalities in each region into two categories (stratum $1=$ urban areas, stratum $2=$ rural areas). At the second stage a random sample of households was drawn ensuring equal probability of selection for each household. At the third stage a member of the household was chosen satisfying the age criteria i.e., being between 65 to 74 years of age. Following the design of a previous study [13] conducted by the Dental School of the University of Athens, two Metropolitan areas of Athens and Thessaloniki (where the majority of population lives) and three major regions Achaia (Patras), loannina and Kastoria, were chosen. Consequently, from within the above mentioned regions of Greece a distinction was made between inhabitants of urban and rural areas.

The subjects were acquainted with the purpose of the study, which had previously been approved by the Committee for Ethics and Research of the Athens Dental School. All subjects provided signed informed consent forms. A self-administrated questionnaire was designed and one dentist trained in OHRQoL terms conducted face-to-face interviews, between October 2007 and September 2009. Participants were asked to evaluate on a 5 -point Likert scale ( $0=$ never, $1=$ hardly ever, $2=$ occasionally, $3=$ fairly often and $4=$ very often) how frequently during the last year they had experienced any of the problems assessed by the validated 14-item OHIP. The examiner also recorded data regarding their socio-demographic profile (e.g., information concerning age, gender, education level and occupation). Specifically for the occupation, distinctions considered were self-standing 
Papaioannou et al. Oral Biology and Dentistry 2015,

business owner, private employee, public employee, retiree, unemployed and homemaker.

Apart from the general score, the results can be broken down into the 7 subscales that represent the different facets or impacts of oral health. These subscales are psychological disability, social disability, handicap, physical disability, physical pain, functional limitation and psychological discomfort. The OHIP-14 has been validated for the Greek language for both adolescents [14] and adults [15].

Besides OHIP-14, the questionnaire also included items regarding self-perceived general and oral health status as well as participants' satisfaction with their oral health status. These data were considered for the assessment of different types of construct validity, given the absence of a universally accepted "gold standard".

We used the SPSS-20 version to estimate the average values of 7 sub-scales of the OHIP-14 and to assess the statistical significance in self perceived health status, in oral and general health. Comparisons were made across demographic, educational and regional criteria. All evaluations of statistical significance were based on two sided tests assessing the statistical significance at 5 percent level.

\section{Results}

From the 5 different regions of Greece, a total number of 501 adults were interviewed. From Athens and Thessaloniki, the 2 major metropolitan areas of Greece in which almost the half of the population of the country can be found, a total 100 subjects from each was included, of which 2 were considered to live in rural conditions for the former and 14 were considered to live in rural conditions on the outskirts of the city for the latter. For the other 3 regions, Patras included a total of 100 subjects with 21 rural, loannina 101 in total with 50 rural and for Kastoria, from a total of 100 participants, those from rural areas numbered 26.

The gender distribution of the sample population was $62.4 \%$ men and $37.6 \%$ women. From the total sample, $17.8 \%$ reported to be smokers. Another important factor that could impact on the results is the educational level of each individual. The majority of $63.4 \%$ reported to have finished lower level of education, $24.5 \%$ middle education, and only $5.8 \%, 5.6 \%$ and $0.6 \%$ for higher, highest and postgraduate education, respectively. For the occupation of the individuals, the large majority of $82.2 \%$ were pensioners while $11.2 \%$ mentioned they were homemakers. The small minority that did continue to work was mainly self-employed (4.4\%), while only $1.2 \%$ was employed by the private sector and $1.0 \%$ in the public.

A Cronbach alpha of 0.89 was determined after internal reliability was tested, which represents a very good internal consistency. There was an impact of oral health on the overall quality of life, which was shown by the subjects overall weighted OHIP-14 score of 2.1 (s.d. 2.7). The metropolitan subjects had a higher score when compared to the non-metropolitan ( 2.4 versus 2.1 , respectively), however when the subjects were distinguished as rural or urban it was the former that reported the higher impact (2.4 vs. 2.2, respectively Figure 1). With the additive method the results present a similar but inverted impact (Figure 2). This meant that the metropolitan subjects presented a slightly lower impact of their oral health on their quality of life (14.7 mean additive score versus 16.4 for the non-metropolitan subjects. Several of the seven subscales of the OHIP-14 tool (Table 1) were found to present differences among rural versus urban populations as well as among those living in metropolitan and non-metropolitan areas. The mean OHIP-14 scores were found to be at a similar level for the two genders: with men having a mean of 2.0 (s.d. 2.7) and women 2.5 (s.d. 2.8). However, for the additive score a significantly higher effect ( $p=0.02$ ) was found for the women

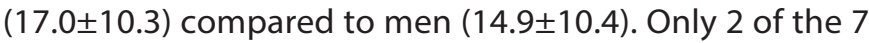
subscales were found to be significantly different between genders: physical pain and the handicap subscale $(p \leq 0.05)$. Concerning the education level of the subjects it was found that in terms of the specific and additive dimensions of the OHIP-14 there are significant differences (Table 2).

The majority of subjects in both rural and urban areas considered their general health to be good $(56 \%$ and $58 \%$, respectively), while $18 \%$ as bad in the rural, triple of that found (6\%)
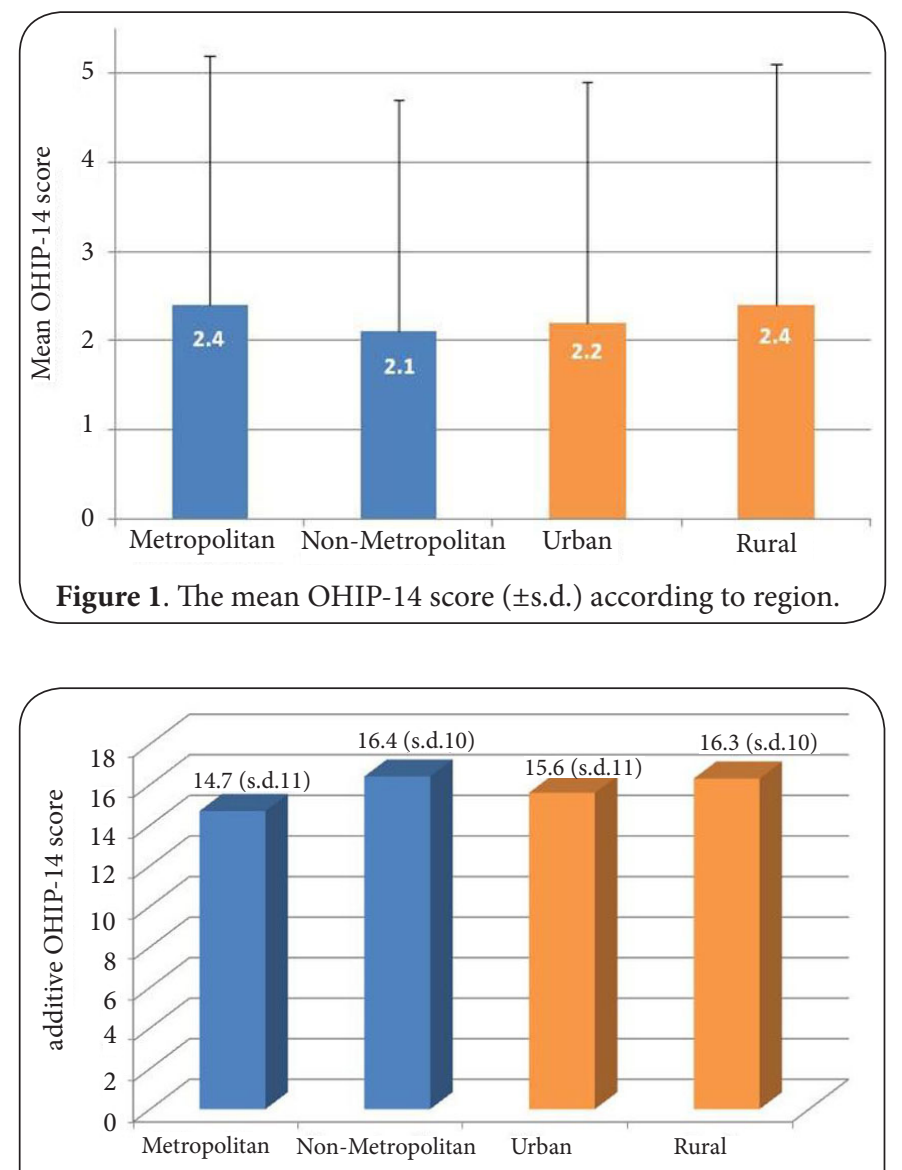

Figure 2. The mean additive OHIP-14 score ( \pm s.d.) according to region. 
Papaioannou et al. Oral Biology and Dentistry 2015,

http://www.hoajonline.com/journals/pdf/2053-5775-3-1.pdf

Table 1. Mean OHIP-14 ( \pm s.d.) for the subscales and total scores according region.

\begin{tabular}{|c|c|c|c|c|c|c|c|c|c|}
\hline Region & $\begin{array}{l}\text { Functional } \\
\text { limitation }\end{array}$ & Physical pain & $\begin{array}{l}\text { Psychological } \\
\text { discomfort }\end{array}$ & $\begin{array}{l}\text { Physical } \\
\text { disability }\end{array}$ & $\begin{array}{l}\text { Psychological } \\
\text { disability }\end{array}$ & $\begin{array}{l}\text { Social } \\
\text { disability }\end{array}$ & Handicap & $\begin{array}{l}\text { OHIP } \\
\text { SCORE }\end{array}$ & $\begin{array}{l}\text { OHIP } \\
\text { ADD }\end{array}$ \\
\hline Urban & $3.0 \pm 2.2$ & $2.5 \pm 2.0$ & $2.0 \pm 2.0$ & $2.2 \pm 2.0$ & $1.5 \pm 2.0$ & $1.1 \pm 1.6$ & $2.3 \pm 1.7$ & $2.2 \pm 2.7$ & $15.6 \pm 11.0$ \\
\hline Rural & $3.0 \pm 2.1$ & $2.6 \pm 2.0$ & $2.8 \pm 1.7$ & $2.3 \pm 1.8$ & $1.2 \pm 2.2$ & $1.4 \pm 1.8$ & $2.1 \pm 1.5$ & $2.4 \pm 2.7$ & $16.3 \pm 10.0$ \\
\hline Metro & $2.8 \pm 2.2$ & $2.5 \pm 2.2$ & $2.8 \pm 2.2$ & $2.0 \pm 2.0$ & $1.5 \pm 2.2$ & $1.0 \pm 1.6$ & $2.3 \pm 1.8$ & $2.4 \pm 2.8$ & $14.7 \pm 11.0$ \\
\hline Non-metro & $3.0 \pm 2.0$ & $2.6 \pm 1.9$ & $3.0 \pm 1.8$ & $2.4 \pm 1.9$ & $1.6 \pm 1.8$ & $1.4 \pm 1.6$ & $2.2 \pm 1.6$ & $2.1 \pm 2.6$ & $16.4 \pm 10.0$ \\
\hline
\end{tabular}

Table 2. Mean OHIP-14 ( \pm s.d.) for the subscales and total scores according to educational level.

\begin{tabular}{|c|c|c|c|c|c|c|c|c|c|}
\hline $\begin{array}{l}\text { Educational } \\
\text { level }\end{array}$ & $\begin{array}{l}\text { Functional } \\
\text { limitation }\end{array}$ & $\begin{array}{l}\text { Physical } \\
\text { pain }\end{array}$ & $\begin{array}{l}\text { Psychological } \\
\text { discomfort }\end{array}$ & $\begin{array}{l}\text { Physical } \\
\text { disability }\end{array}$ & $\begin{array}{l}\text { Psychological } \\
\text { disability }\end{array}$ & $\begin{array}{l}\text { Social } \\
\text { disability }\end{array}$ & Handicap & $\begin{array}{l}\text { OHIP } \\
\text { SCORE }\end{array}$ & $\begin{array}{l}\text { OHIP } \\
\text { ADD }\end{array}$ \\
\hline Elementary & $3.0 \pm 2.0$ & $2.6 \pm 1.9$ & $2.9 \pm 1.9$ & $2.3 \pm 2.0$ & $1.7 \pm 2.0$ & $1.3 \pm 1.6$ & $2.2 \pm 1.6$ & $2.2 \pm 2.7$ & $16.0 \pm 10.3$ \\
\hline Middle & $2.7 \pm 2.1$ & $2.2 \pm 2.0$ & $2.7 \pm 2.0$ & $2.0 \pm 2.0$ & $1.2 \pm 1.7$ & $1.0 \pm 1.6$ & $2.2 \pm 1.6$ & $2.0 \pm 2.7$ & $14.0 \pm 10.2$ \\
\hline High School & $3.7 \pm 2.0$ & $2.9 \pm 2.1$ & $3.0 \pm 1.7$ & $2.3 \pm 1.8$ & $1.6 \pm 1.9$ & $1.2 \pm 1.5$ & $2.7 \pm 2.0$ & $2.3 \pm 3.0$ & $17.0 \pm 9.9$ \\
\hline University & $3.5 \pm 2.4$ & $3.0 \pm 2.2$ & $3.2 \pm 2.2$ & $2.5 \pm 2.1$ & $1.6 \pm 2.0$ & $1.2 \pm 1.6$ & $2.2 \pm 1.7$ & $2.6 \pm 2.9$ & $17.0 \pm 11.2$ \\
\hline Post-graduate & $4.0 \pm 1.7$ & $1.6 \pm 2.0$ & $2.6 \pm 2.0$ & $1.3 \pm 2.3$ & $1.0 \pm 1.7$ & $0.6 \pm 1.2$ & $1.6 \pm 1.5$ & $1.6 \pm 2.0$ & $13.0 \pm 11.3$ \\
\hline
\end{tabular}

for the urban areas (Figure 3). For their oral health (Figure 4), less than $45 \%$ of the subjects in both rural and urban areas judged this factor as being good, while 13\% and $9 \%$ as bad, respectively. Significant correlations were found (at the $p \leq 0.01$ level) for the OHIP-14 score with both self-reported oral and general health. The majority (285 subjects) considered their general health to be good which was reflected in their lower mean OHIP-14 score of 1.7 (s.d. 2.4), in comparison to those responding "bad" with a mean OHIP-14 of 3.5 (s.d. 3.3). For oral health the number considering it to be good was greatly lower $(n=204)$ than for general health. For oral health a number of subjects $(n=49)$ even reported it as being bad, and these individuals had a mean OHIP-14 that reached 4.6 (s.d. 3.2) (Table 3).

The responses to the question, "Are you satisfied with your oral health?" returned a significant correlation $(p \leq 0.01)$ between the OHIP-14 score with oral health satisfaction. The majority of the subjects $(n=359)$ was satisfied and thus had presented a lower impact on their quality of life (mean OHIP-

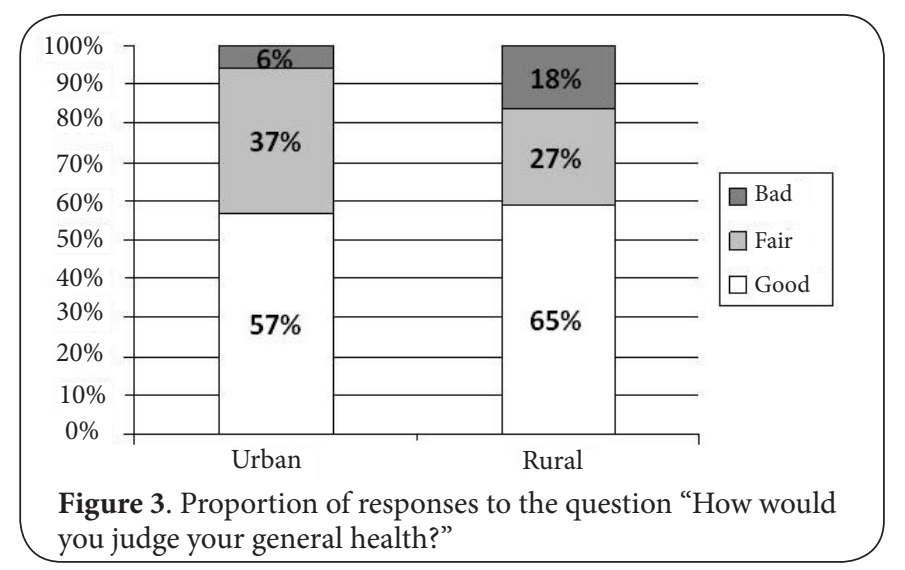

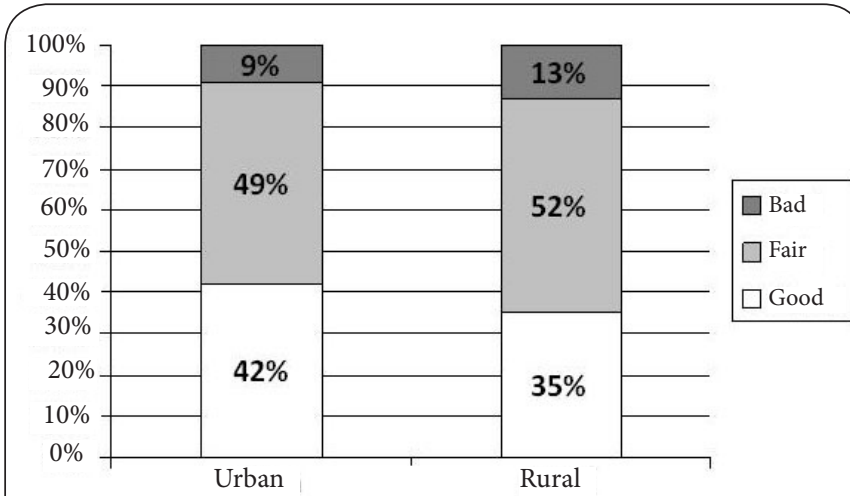

Figure 4. Proportion of responses to the question "How would you judge your oral health?"

Table 3. Mean OHIP-14 ( \pm s.d.) scores according to self-perceived general and oral health.

\begin{tabular}{lcc}
\hline & OHIP vs. General Health & OHIP vs. Oral Health \\
\hline Good & $1.7 \pm 2.4$ & $1.1 \pm 1.7$ \\
Fair & $2.7 \pm 2.9$ & $2.6 \pm 2.8$ \\
Poor & $3.5 \pm 3.3$ & $4.6 \pm 3.2$ \\
\hline
\end{tabular}

14 score of 1.3, s.d. 2.0). Conversely, those that responded that they were not satisfied with their oral health $(n=138)$ had a much higher OHIP-14 score of 4.3 (s.d. 3.1).

Finally, concerning the question "How does your oral health compare to others?" a significant correlation $(p \leq 0.01)$ of the OHIP-14 score was determined with how each individual perceives his oral health against his peers. A higher number of subjects answered "better", a majority of 219 in total, while those answering the "same" were 178, but 53 considered their 
oral health to be worse. The impact score increased quite significantly over the 3 answers $(1.4,2.2$ and 5.6 for Better, Same, and Worse, respectively).

When all the study subjects are grouped according to their education level (Table 2), the subscale of quality of life that is most affected by problems in the oral condition is that of functional limitation. For every education level bad oral health significantly affects good function. It is important also to note that the highest education level (Post-graduate studies) had the lowest overall OHIP-14 score of 1.6, but University level studies in general received the highest score of 2.6.

\section{Discussion}

It has become widely recognized that the effects of diminished health or disease on an individual cannot be determined solely in terms of medical examinations and clinical indices. Although these may allow, where possible, objective meas urements of the overall toll a specific medical situation may have, they are unable to quantify the subjective impact [2]. This subjective impact may be perceived very differently between individuals and can range, depending on the specific characteristics of the disease, from insignificant up to even having a debilitating effect, greatly reducing the quality of life and function of the individual in the community. This in turn has economic and other ramifications to society as a whole, if the performance or well being of member of the society is affected [16]. Furthermore, data on health related quality of life has become a necessity when health care planning, especially funding allocation, is undertaken to maximize the cost/benefit ration of health ventures.

An integral part of the health of an individual, of all ages, is his or her oral health status. Significant oral disease or a poor oral status can be significant factor leading to either physical or psychological incapacitation, or even both. For this reason Oral Health Related Quality of Life (OHRQoL) research has continually grown in importance. Primarily to increase our knowledge of the impact of oral health but what is more important as a guide to preventive and therapeutic dental care provision $[17,18]$.

The present paper presents results of Oral Health Related Quality in a population of senior citizens. For the specific age group of elderly adults, it has been shown in a study by Hebling and Pereira [19] that the OHIP-14 instrument can be considered an instrument of choice, along with 6 other instruments that they set apart out of a larger pool of similar questionnaires. Indeed, the instrument was found here to have a very high internal consistency with a Cronbach a of 0.89 , which reflects the results reported when used for the other age groups $[\mathbf{2 0}, \mathbf{2 1}]$. Moreover, this is the first study to examine a representative sample of this elderly section of the Greek population concerning oral health quality of life.

Previous studies in other senior adult populations found that the majority of subjects report a significant impact of oral health on their daily quality of life, both in a negative and in a positive manner [3,22-24]. The present findings for Greek seniors revealed a medium impact of oral health with a weighted OHIP-14 score of 2.1, higher than the findings for the adolescents (1.2) [20] and young adults (1.1) [21], confirming the previous reports of a relatively low effect for the Greek population as a whole. This finding is somewhat lower than what a similar study found for Norwegian elders [25], which reported an OHIP-14 score of 3.4, as well as to the levels of impact that were reported for South Australians, i.e., 4.8 [23]. Concerning the latter study, there was agreement in that when the subjects were grouped according to their self-rated oral health, they showed significant increases in the OHIP score as the health rating decreased (reaching 4.6 for those considering their oral health as bad; Table 4). Similar findings are found in the study by Jensen \& co-workers [26] in a population of community dwelling elderly who returned worse OHRQoL, using the OHIP-14, with the presence of perceived need for dental treatment or poor self rated general health. However, similarly high levels of health satisfaction were also found, with the majority of the subjects reporting that they were satisfied with their general and oral health conditions. These are points that further emphasize the validity of the present instrument for use in an elderly population.

Table 4. Comparison of the total DMFT scores, focusing on the MT component, and the percentage of subjects presenting periodontal disease from similar population groups to those of the present study and the OHIP-14 scores for these groups.

\begin{tabular}{lllll}
\hline & DMFT $^{*}$ & MT $^{*}$ & $\begin{array}{l}\text { \% Perio Disease* } \\
(\text { CPI 3 \& 4) }\end{array}$ & $\begin{array}{l}\text { Mean } \\
\text { OHIP-14 } \\
\text { score }\end{array}$ \\
\hline $\begin{array}{l}\text { Young adults } \\
\text { (35-44 yrs.) }\end{array}$ & 14.1 & 5.2 & 27.5 & $1.1^{\star *}$ \\
$\begin{array}{l}\text { Senior citizens } \\
\text { (65-74 yrs.) }\end{array}$ & 21.0 & 17.2 & 59.9 & 2.1 \\
\hline
\end{tabular}

${ }^{\star}$ Results presented were obtained from Oulis et al. [13].

${ }^{*}$ Result obtained from Papaioannou et al. [21].

The increase in impact in comparison to the other age groups can probably be accounted for by the increase of severe periodontal disease and tooth loss, that can be found in the older members of the Greek population [27] and that in turn impacts significantly on an individual's quality of life. Although, as mentioned above, the majority did consider their oral health to be satisfactory, when comparing to the younger adults there was a reduction in the perception of oral health as being good, with in increase in those reporting it as 'bad' reaching $13 \%$ (compared to the $4.2 \%$ for the younger adults [21]. As has been previously mentioned, the greatest drawback of this study was the absence of a clinical examination to compliment and enhance the findings of the OHIP-14 questionnaire. However, information of important clinical indices in very similar populations in different regions of Greece is 
Papaioannou et al. Oral Biology and Dentistry 2015,

readily available through the Hellenic pathfinder survey [13] as shown in Table 4. It is clear from the data available from that study that the differences in the age groups (an increase in OHIP score from 1.1 to 2.1) can most likely be explained by the significant difference in clinical status between these groups. Comparing younger adults and senior citizens in Greece, the total number of missing teeth tripled (from 5.2 to 17.2) and the percentage of subjects with periodontal disease more than doubled (reaching a total of $59.9 \%$ of the subjects with a CPI score of 3 or 4). In this way, the finding can be said to concur with those in an adult Swedish population where the highest OHIP score was associated with severe tooth loss [28].

The increase of missing teeth can also account for the increased scores found for functional subscales, especially for functional limitation that reached and surpassed the score of 3. Indeed, McGrath and Bedi [3] found in their study of subjects in the UK that function, especially eating, and psychological factors were of great importance to adults over 65. The psychological discomfort documented here can be considered to be affected, apart from the actual oral condition, by the general outlook of a person which tends to be less pessimistic in younger individuals than older adults. In this group also, as was previously seen in younger adults, the metropolitan subjects had a higher score when compared to the non-metropolitan (2.4 versus 2.1 , respectively). This can probably be attributed again to possible differences in oral health level between the two regions or possibly to a slightly less positive outlook in life in general for the city dwellers. However, when the additive score is compared the tables are turned between the two areas, further blurring any possible distinctions in outlooks between regions. Just the fact of living in a city does not necessarily mean that there will be higher impacts, case in point being the inhabitants of the $2^{\text {nd }}$ largest city of Greece, Thessaloniki, which tended to be on the lower sides of most score. If the low scores of Kastoria are also factored in, one could say that these scores indicate the more care-free nature of inhabitants of northeastern Greece.

Finally, when the distinction urban or rural is made the rural subjects were found to report a slightly higher impact, as seen in both weighted ( 2.2 versus 2.4 ) and additive scores (15.6 versus 16.3). A possible explanation for these differences, as proposed by other authors [29], are the increased presence of barriers in access to care which leads to lower utilization of health services and higher oral impacts.

It has been reported that the education level as well as income can impact on the OHRQoL in an elderly population [30]. In the present study, that there was no significant effect of educational level can probably be attributed to the fact that the larger majority (63.4\%) of the subjects had only finished the lower level of education. Moreover, over $80 \%$ of the subjects were pensioners. Thus, the notion that has been conveyed, namely that the higher the standard of living of an individual the fewer problems he or she encountered with their teeth [27], cannot be confirmed with the present distinctions of the population and the results.

\section{Conclusions}

For the representative sample of Greek senior citizens that took part in the present study, the oral health impacts on the quality of life of the individual's were significant and showed important increase especially as the self-reported level of oral health decreased. Further investigations into the Oral Health Quality of Life in individuals with significant signs of disease, present or past, must be undertaken. Data from such studies would aid in efficiently advocating for the formation of a suitable profile for future dentists to handle an ageing population, as well as underline the need in providing the necessary resources and public funds for dentistry [16]. It is important to place dental and oral health in the proper context and to show the powers that be that this factor affects the ability to function which in turn has more far reaching economic ramifications. This is essential if we are to live up to the aspirations of the WHO's definition of health as "a state of complete physical, mental, and social well-being and not merely the absence of disease or infirmity" [31].

\section{Competing interests}

The authors declare that they have no competing interests.

Authors' contributions

\begin{tabular}{|l|c|c|c|}
\hline Authors' contributions & WP & CJO & JY \\
\hline Research concept and design & -- & $\checkmark$ & $\checkmark$ \\
\hline Collection and/or assembly of data & $\checkmark$ & $\checkmark$ & -- \\
\hline Data analysis and interpretation & $\checkmark$ & -- & $\checkmark$ \\
\hline Writing the article & $\checkmark$ & $\checkmark$ & -- \\
\hline Critical revision of the article & $\checkmark$ & $\checkmark$ & $\checkmark$ \\
\hline Final approval of article & -- & $\checkmark$ & -- \\
\hline Statistical analysis & -- & -- & $\checkmark$ \\
\hline
\end{tabular}

\section{Acknowledgement}

The authors wish to express their gratitude to all the colleagues and collaborators from the different regions of Greece, who either as examiners or members of the board, or coordinators of the local dental societies, contributed to the completion of this coordinated epidemiological survey, conducted as part of the National Program "Assessment and Promotion of the Oral Health of the Hellenic Population", carried out under the auspices of the Hellenic Dental Association in collaboration with the Dental Schools of Athens and Thessaloniki.

\section{Publication history}

Editor: Petros Papagerakis, University of Michigan, USA. Senior Editor: Paul Batchelor, University College London, UK. Received: 31-Oct-2014 Final Revised: 15-Dec-2014 Accepted: 26-Dec-2014 Published: 01-Jan-2015

\section{References}

1. McGrath $C$ and Bedi R. Measuring the impact of oral health on life quality in two national surveys - functionalist versus hermeneutic approaches. Community Dent Oral Epidemiol. 2002; 30:254-9. | Article PubMed 
Papaioannou et al. Oral Biology and Dentistry 2015,

2. Larson JS. The conceptualization of health. Med Care Res Rev. 1999; 56:123-36. | Article | PubMed

3. McGrath $C$ and Bedi R. The importance of oral health to older people's quality of life. Gerodontology. 1999; 16:59-63. | Article I PubMed

4. John MT, LeResche L, Koepsell TD, Hujoel P, Miglioretti DL and Micheelis W. Oral health-related quality of life in Germany. Eur J Oral Sci. 2003; 111:483-91. | Article | PubMed

5. US Department of Health and Human Services: Oral Health in America: A Report of the Surgeon General. NIH publication 00-4713. Rockville, MD: US Department of Health and Human Services, National Institute of Dental and Craniofacial Research, National Institutes of Health. 2000; 7. | Website

6. Slade GD. Measuring Oral Health and Quality of Life. 1997. I Pdf

7. Garratt A, Schmidt L, Mackintosh A and Fitzpatrick R. Quality of life measurement: bibliographic study of patient assessed health outcome measures. BMJ. 2002; 324:1417. | Article | PubMed Abstract | PubMed Full Text

8. Slade GD and Spencer AJ. Development and evaluation of the Oral Health Impact Profile. Community Dent Health. 1994; 11:3-11. | Article | PubMed

9. Slade GD. Derivation and validation of a short-form oral health impact profile. Community Dent Oral Epidemiol. 1997; 25:284-90. | Article | PubMed

10. Locker D. Measuring oral health: a conceptual framework. Community Dent Health. 1988; 5:3-18. | PubMed

11. World Health Organization. International classification of impairments, disabilities and handicaps. Geneva. 1980. I Pdf

12. Allen PF and Locker D. Do item weights matter? An assessment using the oral health impact profile. Community Dent Health. 1997; 14:133-8. | Article | PubMed

13. Oulis C, Theodorou M, Mastrogiannaki T, Mamai-Chomata E, Polychronopoulou A and Athanasouli T. Oral health status and treatment needs of the Hellenic population - a pathfinder survey-proposals for improvement. Hellenic Stomatological Review. 2009; 53:97-120. | Pdf

14. Roumani T, Oulis CJ, Papagiannopoulou V and Yfantopoulos J. Validation of a Greek version of the oral health impact profile (OHIP-14) in adolescents. Eur Arch Paediatr Dent. 2010; 11:247-52. | Article | PubMed

15. Papagiannopoulou V, Oulis CJ, Papaioannou W, Antonogeorgos G and Yfantopoulos J. Validation of a Greek version of the oral health impact profile (OHIP-14) for use among adults. Health Qual Life Outcomes. 2012; 10:7. | Article | PubMed Abstract | PubMed Full Text

16. Reisine ST. Dental health and public policy: the social impact of dental disease. Am J Public Health. 1985; 75:27-30. | PubMed Abstract | PubMed Full Text

17. Nagarajan $S$ and Chandra RV. Perception of oral health related quality of life (OHQoL-UK) among periodontal risk patients before and after periodontal therapy. Community Dent Health. 2012; 29:90-4. | Article | PubMed

18. Wong RM, Ng SK, Corbet EF and Keung Leung W. Non-surgical periodontal therapy improves oral health-related quality of life. J Clin Periodontol. 2012; 39:53-61. | Article | PubMed

19. Hebling E and Pereira AC. Oral health-related quality of life: a critical appraisal of assessment tools used in elderly people. Gerodontology. 2007; 24:151-61. I Article I PubMed

20. Papaioannou W, Oulis CJ, Latsou D and Yfantopoulos J. Oral health related quality of life of Greek adolescents: a cross-sectional study. Eur Arch Paediatr Dent. 2011; 12:146-50. | Article | PubMed

21. Papaioannou W, Oulis CJ, Latsou D and Yfantopoulos J. Oral healthrelated quality of life of greek adults: a cross-sectional study. Int J Dent. 2011; 2011:360292. | Article | PubMed Abstract | PubMed Full Text

22. McGrath $C$ and Bedi R. A study of the impact of oral health on the quality of life of older people in the UK--findings from a national survey. Gerodontology. 1998; 15:93-8. I Article | PubMed

23. Brennan DS and Singh KA. General health and oral health self-ratings, and impact of oral problems among older adults. Eur J Oral Sci. 2011;
119:469-73. | Article | PubMed

24. Fuentes-Garcia A, Lera L, Sanchez H and Albala C. Oral health-related quality of life of older people from three South American cities. Gerodontology. 2013; 30:67-75. | Article I PubMed

25. Dahl KE, Wang NJ, Holst D and Ohrn K. Oral health-related quality of life among adults 68-77 years old in Nord-Trondelag, Norway. Int J Dent Hyg. 2011; 9:87-92. | Article | PubMed

26. Jensen PM, Saunders RL, Thierer T and Friedman B. Factors associated with oral health-related quality of life in community-dwelling elderly persons with disabilities. J Am Geriatr Soc. 2008; 56:711-7. | Article | PubMed

27. Special Eurobarometer 330. Oral Health. 2010. I Pdf

28. Einarson S, Gerdin EW and Hugoson A. Oral health impact on quality of life in an adult Swedish population. Acta Odontol Scand. 2009; 67:85-93. | Article | PubMed

29. Shah N and Sundaram KR. Impact of socio-demographic variables, oral hygiene practices, oral habits and diet on dental caries experience of Indian elderly: a community-based study. Gerodontology. 2004; 21:4350. | Article | PubMed

30. Makhija SK, Gilbert GH, Boykin MJ, Litaker MS, Allman RM, Baker PS, Locher $\mathrm{JL}$ and Ritchie CS. The relationship between sociodemographic factors and oral health-related quality of life in dentate and edentulous community-dwelling older adults. J Am Geriatr Soc. 2006; 54:1701-12. | Article I PubMed

31. WHO. World Health Organization Constitution. Geneva, Switzerland: World Health Organization. 1948. I Pdf

\section{Citation:}

Papaioannou W, Oulis CJ and Yfantopoulos J. The oral health related quality of life in different groups of senior citizens as measured by the OHIP-14 questionnaire.

Oral Biol Dent. 2015; 3:1.

http://dx.doi.org/10.7243/2053-5775-3-1 